Article

\title{
Variance of the Gait Parameters and Fraction of Double-Support Interval for Determining the Severity of Parkinson's Disease
}

\author{
Sana M. Keloth ${ }^{1}$, Sridhar P. Arjunan ${ }^{2, *}{ }^{1 / D}$ and Dinesh K. Kumar ${ }^{1}(\mathbb{D}$ \\ 1 Biosignals Lab., School of Engineering, RMIT University, GPO Box 2476, Melbourne, VIC 3001, Australia; \\ s3614093@student.rmit.edu.au (S.M.K.); dinesh@rmit.edu.au (D.K.K.) \\ 2 Center for Human Movement Research and Analysis, Department of Electronics and Instrumentation \\ Engineering, SRM Institute of Science and Technology, Chennai 603203, India \\ * Correspondence: sridhar_arjunan@ieee.org
}

Received: 12 December 2019; Accepted: 10 January 2020; Published: 13 January 2020

\begin{abstract}
The aim of this study was to determine the gait features that are most suitable for the quantified assessment of the severity of Parkinson's disease (PD). This study computed the mean and variance of the four phases of gait intervals, i.e., stride, swing, stance and double-support intervals, and lateral difference to determine the difference between three groups, i.e., control subjects and PD patients with two severity levels (early and advanced stage) of the disease, PD1 and PD2. Data from 31 subjects were used in the study. The data were obtained from the public database $(16$ control healthy subjects, 6 Parkinson's disease patients with early stages, and 9 Parkinson's disease patients with advanced stages based on the Hoehn and Yahr scale). The main outcome measure of the study was the group difference of the four gait interval parameters and the statistical significance of this difference. The results show that there was a significant increase in the variance of the four gait intervals with the severity of the disease. However, there was no significant difference in the mean values between the three groups. It was also observed that the fraction corresponding to the double-support interval was significantly higher for PD patients. This study has shown that the variance of the gait parameters and the fraction of double-support interval are associated with the severity of PD and may be suitable measures for a quantified evaluation of the disease.
\end{abstract}

Keywords: gait; double support; Parkinson's disease; variance; lateral differences

\section{Introduction}

The walking style of Parkinson's disease (PD) patients, the Parkinsonian gait (PG), is characterized by small shuffling steps and hypokinesia in comparison with normal subjects, whose gait is rhythmic when walking on an even surface [1]. There is significant deterioration of the gait of PD patients with the progression of the disease [2-4], and this is a major cause of their falls and injuries [2,5,6].

In comparison with control subjects, PD patients have reduced stride length $[7,8]$ and walking speed [7,9] with increased double-support duration [10-13] during free ambulation on an even surface. Neurologists monitor their patients by observing their gait, to determine the progression of the disease and the efficacy of treatments [14-16]. This requires a significant amount of time on the part of experienced neurologists, and there is a need for quantifiable gait analysis that can be performed without the extensive infrastructure used to monitor the severity of PD.

Many studies have quantified the difference in the gait of PD and control subjects by using devices such as insole sensors to record the gait parameters [17-20]. It has been found that there is higher variability $[18,21,22]$ and changed fractal properties $[17,18,23,24]$ of the inter-stride intervals in PD 
patients. Osamu et al. [25] studied the spectral properties of stride variability and found that the range of power spectrum was four times larger for PD than control. Krishnan et al. [26] have developed a statistical model to describe the higher gait variability in PD patients. This increase has been proposed for diagnostics and monitoring the progression of the disease.

A number of factors can influence the change in the gait of a person, and the inter-stride interval is very gross and unspecific. Besides neurological disorders such as PD, a skeletal disease such as arthritis can also reduce the speed of walking and increase the variability in the inter-stride interval. Further analysis of the gait is required to identify the changes due to this disorder.

Gait has four major subcomponents that can be estimated from the heel-strike data: stride, swing, stance, and double-support intervals. The swing phase resembles the motion of a free-swinging pendulum [27,28], requiring minimum neuromuscular control, and is thus expected to be least disturbed by a neurological disorder. This is confirmed by the observation that in PD patients, swing-time variability is not affected by changes in gait speed [29]. The stance phase, on the other hand, requires the simultaneous control of multiple muscles and is most likely to be affected by neurological disorders [23]. This explains the significant increase in the percentage of the stance phase in PD patients when compared to that of the control group [30], and the increased double-support duration [30,31]. This paper reports a statistical analysis of the four phases of the gait of PD and control subjects to identify which of these are most affected by disease and could thus be considered for diagnosing or monitoring PD.

The other important factor of gait that can be obtained from the heel-strike data is lateral asymmetry. There is a natural asymmetrical gait pattern in humans due to limb dominance [32]. During walking, the nondominant lower limb contributes more towards support, and the dominant limb contributes more to propulsion [33]. However, loss of limb coordination in producing rhythmic motion may cause pathological asymmetric gait [34]. This project has also investigated the lateral difference in the gait parameters for PD patients.

\section{Materials and Methods}

\subsection{Details of the Dataset}

The study has investigated a public dataset [35] of the gait data of 31 subjects: 16 control subjects, referred to as CON, 6 patients with early stages of PD, referred to as PD1, and 9 with advanced stages of PD, referred to as PD2 [36]. The severity of PD was based on the Hoehn and Yahr scale (H\&Y); PD1 corresponded to a H\&Y value between 1 and 2.5, and PD2 to a H\&Y value between 3 and 4 . The anthropometric details of the subjects are listed in Table 1.

Table 1. Anthropometric details of all subjects.

\begin{tabular}{cccc}
\hline Anthropometric Parameter & CON (n= 16) & PD1 $(\mathbf{n = 6 )}$ & PD2 (n= 9) \\
\hline Age (years) & $45.66 \pm 9.14$ & $66 \pm 14.3$ & $67.33 \pm 8.7$ \\
\hline Height $(\mathrm{m})$ & $1.83 \pm 0.085$ & $1.88 \pm 0.12$ & $1.85 \pm 0.17$ \\
\hline Weight $(\mathrm{kg})$ & $68.935 \pm 10.75$ & $81.33 \pm 14.3$ & $70.88 \pm 17.66$ \\
\hline Gender (male: female) & $2: 14$ & $1: 5$ & $4: 5$ \\
\hline
\end{tabular}

The data was recorded using bilateral insole force sensors while the subjects walked their preferred speed along a $160 \mathrm{~m}$ long level ground for $6 \mathrm{~min}$ without stopping. The first $30 \mathrm{~s}$ of each subject's time series were removed to minimize any start-up effects.

\subsection{Data Analysis}

The database consists of the four gait parameters: stride interval, swing interval, stance interval, and double-support interval, shown in Figure 1. 


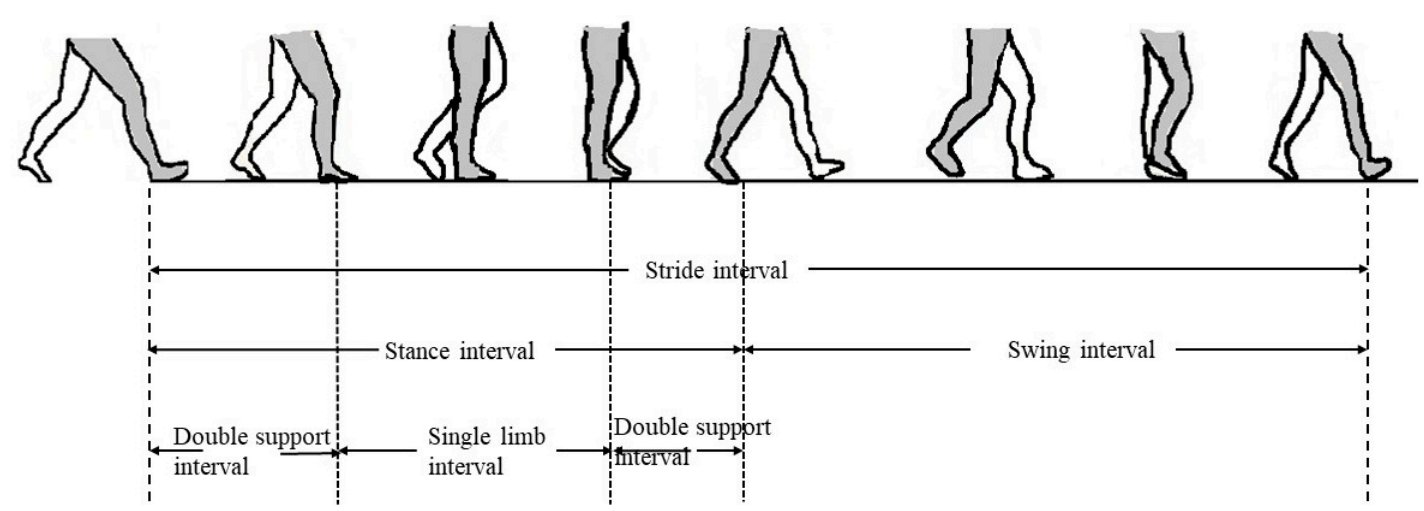

Figure 1. Representation of gait intervals.

The first step was the visualization of the data, which was done by plotting the histogram of the four parameters for each side and for each subject. The next step was computing the mean and variance of the four parameters for each subject and for both the right and left sides, i.e., mean stride interval $\left(\mu_{s t}\right)$, mean swing interval $\left(\mu_{s w}\right)$, mean stance interval $\left(\mu_{s t a}\right)$, mean double-support interval $\left(\mu_{d s}\right)$, variance stride interval $\left(\sigma_{s t}\right)$, variance swing interval $\left(\sigma_{s w}\right)$, variance stance interval $\left(\sigma_{s t a}\right)$, and variance double-support interval $\left(\sigma_{d s}\right)$, with $\sigma_{d s}$ being common for the left and right sides.

The stride interval was analyzed to determine the ratio of the stance and swing intervals. This was performed to test whether there was a relative increase in the stance phase among PD patients, and this increased with the severity of the disease.

\subsection{Statistical Analysis}

The following statistical analysis test was conducted for this study:

(a) Normality test

Prior to the nonparametric test, the Shapiro-Wilk test was conducted to check for normal distribution of the raw data by considering all the gait parameters. The Shapiro-Wilk test provides the highest power of distribution when compared to other tests, like the Kolmogorov-Smirnov test or the Lilliefors correction test [37].

(b) Nonparametric tests

In order to test the significant difference between the groups, a nonparametric test, the Kruskal-Wallis test, was performed [38]. The variance and mean of gait intervals (variance stride interval $\left(\sigma_{s t}\right)$ and variance swing interval $\left(\sigma_{s w}\right)$, variance stance interval $\left(\sigma_{s t a}\right)$, variance double-support interval $\left(\sigma_{d s}\right)$ and mean stride interval $\left(\mu_{s t}\right)$, mean swing interval $\left(\mu_{s w}\right)$, mean stance interval $\left(\mu_{s t a}\right)$, and mean double-support interval $\left.\left(\mu_{d s}\right)\right)$ were considered for checking the level of significance between the groups.

\section{Results}

\subsection{Histogram}

A histogram was used for the graphical visualization of the data to understand the difference in shape and spread of the data in each group [39]. The group-representative histograms of stride, swing, stance, and double-support intervals of the right leg on the three groups (CON, PD1, and PD2, with a randomly selected subject from each group) are shown in Figure 2. The distributions are unimodal for all four parameters, and the CON subjects have narrow distributions. The distributions of PD1 are less constricted when compared to those of CON, and those of PD2 were the most spread. These also show that there was a noticeable increase in the mean stride, stance, and double-support intervals from CON to PD1 and PD2. However, a decrease in the mean swing interval was observed when PD2 was compared to CON. 


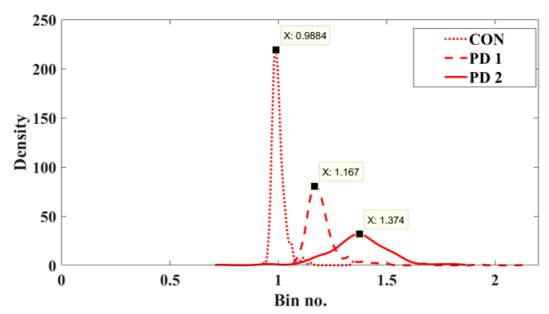

(a)

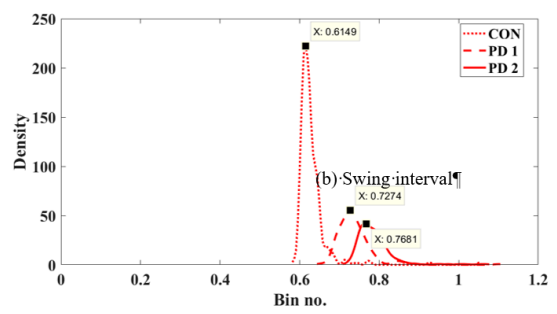

(c)

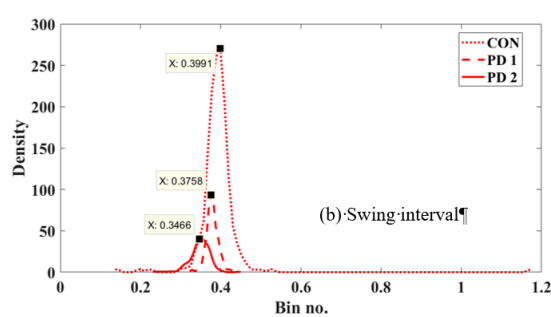

(b)

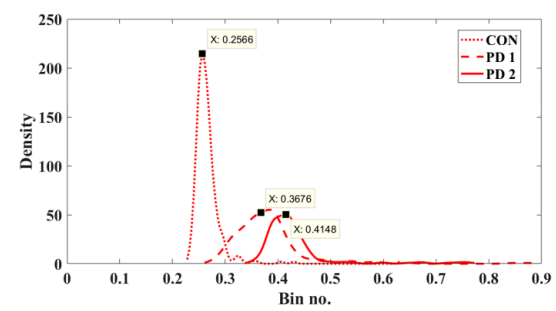

(d)

Figure 2. Histogram plot of subjects randomly selected from each group: (a) stride, (b) swing, (c) stance, and (d) double-support interval for CON, PD1, and PD2 subjects, respectively.

\subsection{Lateral Differences}

Table 2 shows the mean and variance of left and right leg gait parameters for CON, PD1, and PD2 subjects. The subscripts $l$ and $r$ denote the left and right leg values of the gait parameters. This shows that while there was a small difference between the left and right leg parameters for all subject groups, the statistical analysis did not show any statistically significant lateral difference $(p<0.05)$. There was no information in the database regarding the dominant leg, and thus, the dominant leg-based study was not performed. Further analysis was performed only on the right leg data, which was based on the assumption that the majority of the subjects were right-dominant.

Table 2. Comparison between left and right leg mean $( \pm \mathrm{SD})$ and variance $( \pm \mathrm{SD})$ of gait parameters for different groups.

\begin{tabular}{|c|c|c|c|c|c|c|c|}
\hline Gait Intervals & Statistical Parameter & CON & $p$-Value & PD1 & $p$-Value & PD2 & $p$-Value \\
\hline \multirow{4}{*}{ Stride interval } & $\mu_{s t, l}$ & $1.095 \pm 0.093$ & \multirow{2}{*}{0.462} & $1.215 \pm 0.271$ & \multirow{2}{*}{0.872} & $1.153 \pm 0.123$ & \multirow{2}{*}{0.894} \\
\hline & $\mu_{s t, r}$ & $1.071 \pm 0.047$ & & $1.122 \pm 0.102$ & & $1.147 \pm 0.119$ & \\
\hline & $\sigma_{s t, l}$ & $0.002 \pm 0.003$ & \multirow{2}{*}{0.497} & $0.005 \pm 0.005$ & \multirow{2}{*}{0.872} & $0.009 \pm 0.010$ & \multirow{2}{*}{0.964} \\
\hline & $\sigma_{s t, r}$ & $0.001 \pm 0.001$ & & $0.005 \pm 0.004$ & & $0.007 \pm 0.006$ & \\
\hline \multirow{4}{*}{ Swing interval } & $\mu_{\mathrm{sw}, l}$ & $0.396 \pm 0.039$ & \multirow{2}{*}{0.282} & $0.389 \pm 0.035$ & \multirow{2}{*}{0.109} & $0.364 \pm 0.063$ & \multirow{2}{*}{0.757} \\
\hline & $\mu_{s w, r}$ & $0.381 \pm 0.030$ & & $0.368 \pm 0.037$ & & $0.361 \pm 0.067$ & \\
\hline & $\sigma_{s w, l}$ & $0.0004 \pm 0.0002$ & \multirow{2}{*}{0.763} & $0.0010 \pm 0.0005$ & \multirow{2}{*}{1} & $0.002 \pm 0.001$ & \multirow{2}{*}{0.825} \\
\hline & $\sigma_{s w, r}$ & $0.0004 \pm 0.0002$ & & $0.0009 \pm 0.0003$ & & $0.002 \pm 0.001$ & \\
\hline \multirow{4}{*}{ Stance interval } & $\mu_{\text {sta }, l}$ & $0.682 \pm 0.033$ & \multirow{2}{*}{0.821} & $0.732 \pm 0.078$ & \multirow{2}{*}{0.336} & $0.791 \pm 0.107$ & \multirow{2}{*}{0.825} \\
\hline & $\mu_{\text {sta }, r}$ & $0.689 \pm 0.032$ & & $0.753 \pm 0.089$ & & $0.778 \pm 0.104$ & \\
\hline & $\sigma_{s t a, l}$ & $0.002 \pm 0.002$ & \multirow{2}{*}{0.174} & $0.0042 \pm 0.003$ & \multirow{2}{*}{0.872} & $0.005 \pm 0.004$ & \multirow[t]{2}{*}{0.658} \\
\hline & $\sigma_{s t a, r}$ & $0.001 \pm 0.001$ & & $0.004 \pm 0.004$ & & $0.010 \pm 0.017$ & \\
\hline
\end{tabular}

\subsection{Features of Stride, Swing, Stance, and Double-Support Interval}

Figure 3 shows the group mean for the four parameters (stride, swing, stance, and double-support intervals) for the three groups, regarding CON $(n=16)$, PD1 $(n=6)$, and PD2 $(n=9)$ subjects. The error bars represent the standard deviation of the mean gait interval calculated for each group. Figure 4 shows the variance of the four gait phases (stride, swing, stance, and double-support intervals) for CON ( $n=16)$, PD1 ( $=6)$, and PD2 ( $=9)$ subjects, and the statistical significance results are shown in Table 3. 

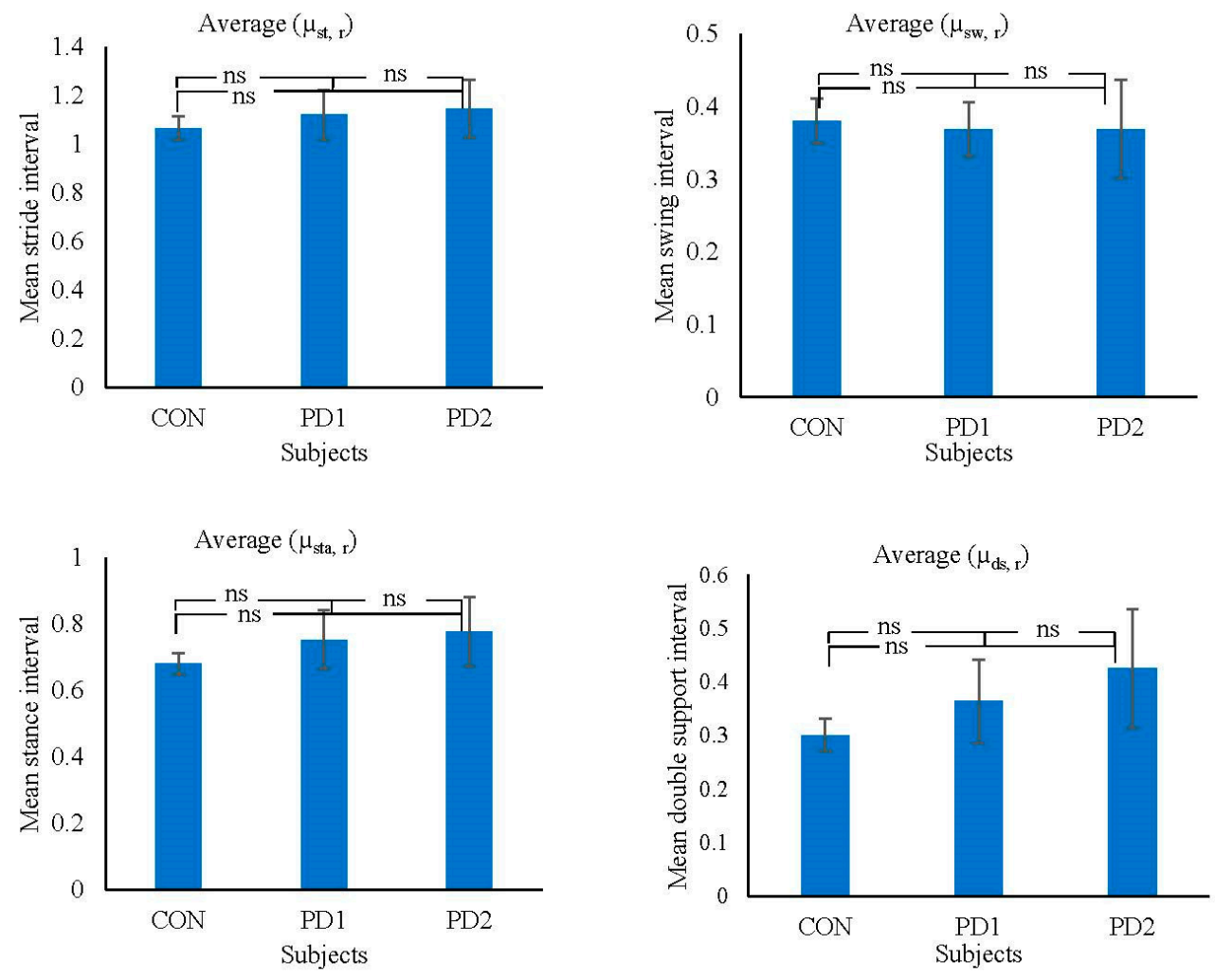

Figure 3. Bar chart showing the mean stride, swing, stance, and double-support intervals for CON, PD1, and PD2 subjects (significance $(p)=$ nonsignificant (ns)).
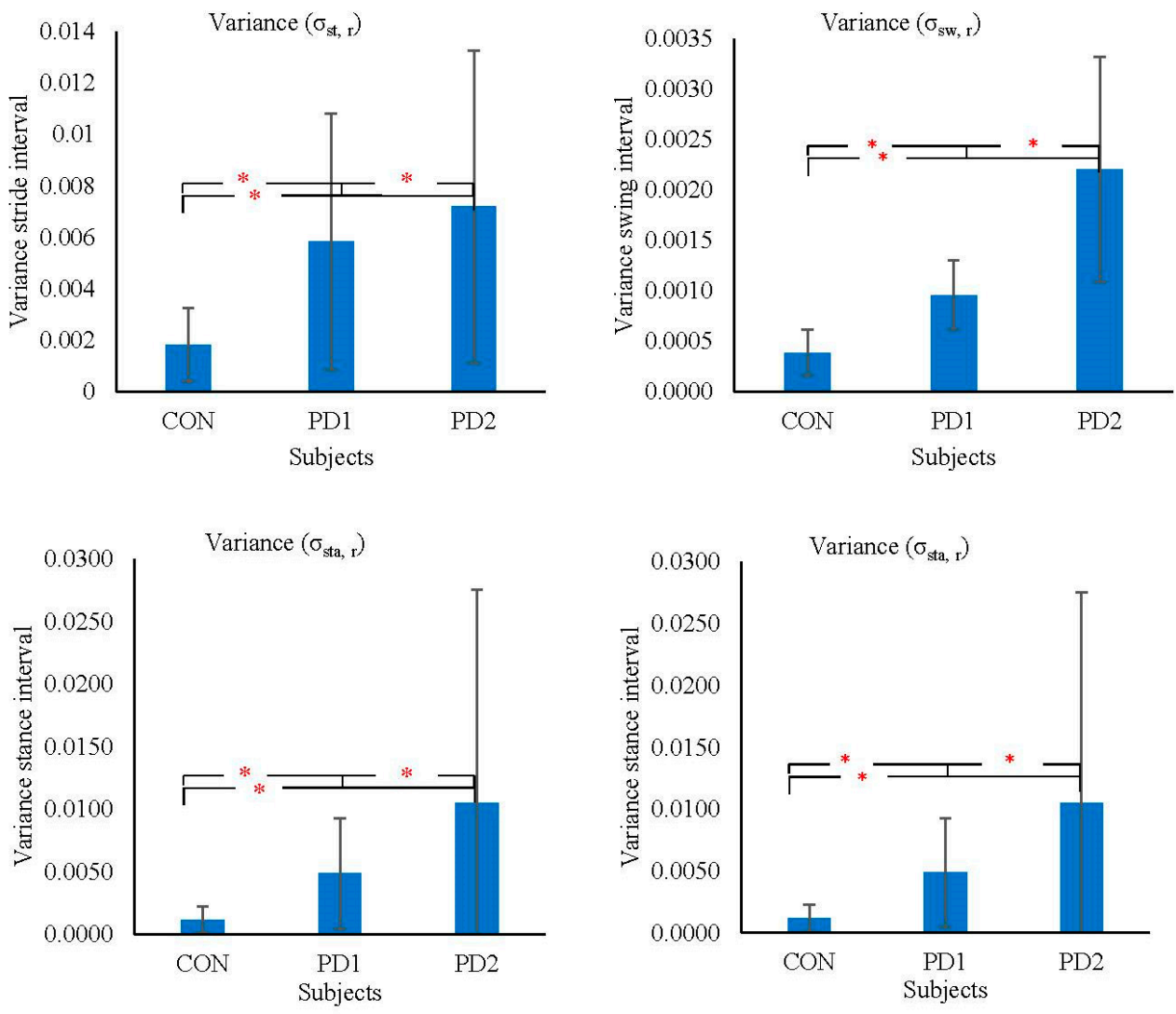

Figure 4. Bar chart showing the variance in stride, swing, stance, and double-support intervals for CON, PD1, and PD2 subjects, respectively (* $p$ (significance) $<0.05$, ns (nonsignificant). 
Table 3. Comparison between the mean $( \pm \mathrm{SD})$ and variance $( \pm \mathrm{SD})$ of gait parameters for CON, PD1, and PD2 groups, and the $p$-values for statistical significance.

\begin{tabular}{|c|c|c|c|c|c|}
\hline Gait Intervals & Statistical Parameter & $\mathrm{CON}$ & PD1 & PD2 & $p$-Value \\
\hline \multirow{2}{*}{ Stride interval } & $\mu_{s t, r}$ & $1.071 \pm 0.047$ & $1.122 \pm 0.102$ & $1.147 \pm 0.119$ & 0.194 \\
\hline & $\sigma_{s t, r}$ & $0.001 \pm 0.001$ & $0.005 \pm 0.004$ & $0.007 \pm 0.006$ & $0.0005^{*}$ \\
\hline \multirow{2}{*}{ Swing interval } & $\mu_{s w, r}$ & $0.381 \pm 0.030$ & $0.368 \pm 0.037$ & $0.361 \pm 0.067$ & 0.518 \\
\hline & $\sigma_{s w, r}$ & $0.0004 \pm 0.0002$ & $0.0009 \pm 0.0003$ & $0.002 \pm 0.001$ & 0.00003 * \\
\hline \multirow{2}{*}{ Stance interval } & $\mu_{\text {sta }, r}$ & $0.689 \pm 0.032$ & $0.753 \pm 0.089$ & $0.778 \pm 0.104$ & 0.051 \\
\hline & $\sigma_{\text {sta, } r}$ & $0.001 \pm 0.001$ & $0.004 \pm 0.004$ & $0.010 \pm 0.017$ & $0.0004^{*}$ \\
\hline \multirow{2}{*}{ Double support } & $\mu_{d s, r}$ & $0.301 \pm 0.0308$ & $0.363 \pm 0.077$ & $0.425 \pm 0.1106$ & 0.081 \\
\hline & $\sigma_{d s, r}$ & $0.0020 \pm 0.003$ & $0.00441 \pm 0.0032$ & $0.0090 \pm 0.0094$ & $0.005 *$ \\
\hline
\end{tabular}

From Figure 3, Figure 4, and Table 3, it may be observed that:

- The mean of all the four gait parameters (stride interval, swing interval, stance interval, and double-support interval) was the lowest for CON, higher for PD1, and the maximum for PD2. However, the difference is not statistically significant when CON was compared with PD1, CON was compared with PD2, and PD1 was compared with PD2.

- The variance of all the four gait parameters (stride interval, swing interval, stance interval, and double-support interval) was the lowest for CON, higher for PD1, and the maximum for PD2. The group differences of all four parameters were statistically significant when CON was compared with PD1, CON was compared with PD2, and PD1 was compared with PD2.

Figure 5 shows the percentage of stance, swing, and double-support intervals for CON, PD1, and PD2 subjects, respectively. From Figure 5, it may be observed that the percentage of stance and swing phases was statistically significant between CON and PD1, and CON and PD2, but not between PD1 and PD2, while the double-support interval was statistically significant between CON and PD1, $\mathrm{CON}$ and PD2, and PD1 and PD2. The statistical significance of all the three groups compared is shown in Table 4.
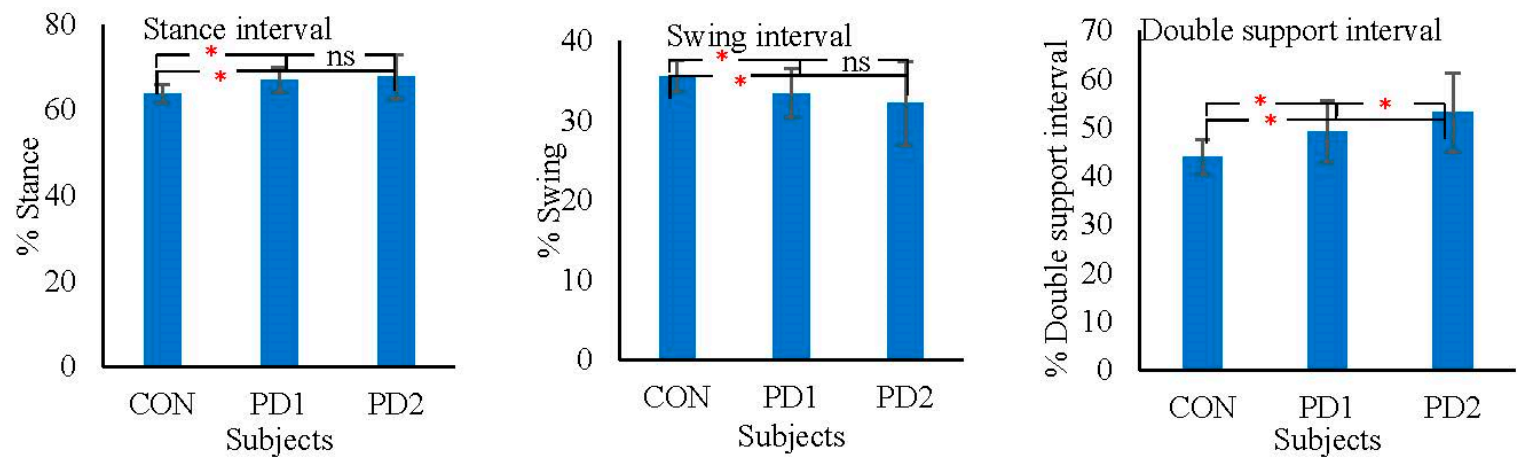

Figure 5. Bar chart showing the percentage of stance, swing, and double-support intervals for different groups ${ }^{*} p$ (significance) $<0.05$, ns (nonsignificant). 
Table 4. Percentage of stance, swing, and double-support intervals when CON, PD1, and PD2 groups are compared.

\begin{tabular}{ccccc}
\hline Gait & CON (\%) & PD1 (\%) & PD2 (\%) & $p$-Value \\
\hline Stance interval & $63.85 \pm 2.23$ & $67.0 \pm 3.08$ & $67.76 \pm 5.21$ & 0.0295 * \\
Swing interval & $35.63 \pm 1.73$ & $33.04 \pm 3.80$ & $32.23 \pm 5.2$ & 0.0492 * \\
Double-support interval & $44.10 \pm 3.58$ & $49.20 \pm 6.3$ & $53.22 \pm 8.15$ & 0.0021 * \\
\hline \multicolumn{5}{c}{ * significance $<0.05}$.
\end{tabular}

\section{Discussion}

\subsection{Lateral Differences}

The results show that there was no significant lateral difference in the mean and variance of the four parameters. This study has shown that there was a difference in the histograms of the CON, PD1, and PD2 groups, and the spread of the distribution was greater for patients with higher severity of the disease. The analysis of the gait data revealed that there was no significant difference in the mean values of the gait parameters (stride interval, swing interval, stance interval, and double-support interval) with the severity of the disease, but that their variance was significantly higher for PD when compared with CON subjects. It was also observed that the variance increased with the severity of the disease.

\subsection{Features of Stride, Swing, Stance, and Double-Support Interval}

Our analysis has shown that there was a significant increase in variance among the PD patients when compared with the control subjects, and that the difference was greater for the higher severity of the disease. This is in line with the observations of $[18,25,26,40-43]$. The increased variability in the stride-interval is associated with falls $[19,44-47]$, and this finding shows that PD patients have a higher risk of falls.

While earlier studies have shown that there is an increase in the double-support duration in PD patients [30,31], our findings did not find this increase to be statistically significant. We have shown that the variability of the stance interval and the double-stance interval was higher for PD patients and increased with the severity of the disease. This increase in the variability indicates poor coordination and loss of rhythmicity and may be considered for quantifying the severity of the disease and monitoring the progress of the patients.

This study found that there was a significant increase in the fraction of the stance interval when compared with the swing interval of PD patients, and that this decreased with the severity of the disease. The percentage of the stance interval for PD2 patients increased by $3.91 \%$, while the double-support interval increased by $9.12 \%$, and the swing interval decreased by $3.4 \%$ when compared to that of the CON subjects. This may be attributed to a fear of falls, and hence, the sense of urgency for PD patients to remain in their double-support phase. This fraction may also be suitable for estimating the severity of the disease and monitoring the progress of PD patients.

\subsection{Study Limitations}

This work has demonstrated that there was a significant PD severity group difference in the gait parameters recorded using insole sensors. The effective use of this technique for monitoring the progress of the PD will require further investigation, considering a greater number of subjects in each group, the effect of factors such as age, gender, and fatigue, and labeling the dominant side. It is also essential to develop the framework for the selection of the device and the measurement protocol to ensure the reproducibility of the recordings. 


\section{Conclusions}

This study observed that there is no bilateral difference in the gait parameters of PD patients when compared with those of the CON subjects, and hence, further analysis was performed only on the right leg data. It was found that the mean values of the four gait parameters are not statistically different for $\mathrm{PD}$ and $\mathrm{CON}$ subjects; however, there is a significant increase in the variance of these gait parameters. The results also showed that while the difference in the mean values of the gait parameters between the PD and CON subjects was not significant, there was a significant increase in the fraction of the double-stance phase. This study showed that the variance and fraction of the gait parameters can be used to measure the progress of the disease and estimate its severity.

Author Contributions: Conceptualization, S.P.A., D.K.K., S.M.K.; Data curation, S.M.K.; Formal analysis, S.M.K.; Methodology, S.M.K.; Project administration, D.K.K.; Supervision, S.P.A. and D.K.K.; Writing-original draft, S.M.K.; Writing-review \& editing, S.P.A. and D.K.K. All authors have read and agreed to the published version of the manuscript.

Funding: This research received no external funding.

Conflicts of Interest: The authors declare no conflicts of interest.

\section{References}

1. Peng, C.K.; Hausdorff, J.M.; Ladin, Z.; Wei, J.Y.; Goldberger, A.L. Is walking a random walk? Evidence for long-range correlations in stride interval of human gait. J. Appl. Physiol. 1995, 78, 349-358.

2. Allcock, L.M.; Rowan, E.N.; Steen, I.N.; Wesnes, K.; Kenny, R.A.; Burn, D.J. Impaired attention predicts falling in Parkinson's disease. Parkinsonism Relat. Disord. 2009, 15, 110-115. [CrossRef] [PubMed]

3. Balash, Y.; Peretz, C.; Leibovich, G.; Herman, T.; Hausdorff, J.M.; Giladi, N. Falls in outpatients with Parkinson's disease: frequency, impact and identifying factors. J. Neurol. 2005, 252, 1310-1315. [CrossRef] [PubMed]

4. Bloem, B.R.; Grimbergen, Y.A.; Cramer, M.; Willemsen, M.; Zwinderman, A.H. Prospective assessment of falls in Parkinson's disease. J. Neurol. 2001, 248, 950-958. [CrossRef]

5. Contreras, A.; Grandas, F. Risk of falls in Parkinson's disease: A cross-sectional study of 160 patients. Parkinson Dis. 2012, 2012, 1-10. [CrossRef]

6. Latt, M.D.; Lord, S.R.; Morris, J.G.; Fung, V.S. Clinical and physiological assessments for elucidating falls risk in Parkinson's disease. Mov. Disord. 2009, 24, 1280-1289. [CrossRef]

7. Sofuwa, O.; Nieuwboer, A.; Desloovere, K.; Willems, A.M.; Chavret, F.; Jonkers, I. Quantitative gait analysis in Parkinson's disease: comparison with a healthy control group. Arch. Phys. Med. Rehabil. 2005, 86, 1007-1013. [CrossRef]

8. Morris, M.; Iansek, R.; Matyas, T.; Summers, J. Abnormalities in the stride length-cadence relation in parkinsonian gait. Mov. Disord. 1998, 13, 61-69. [CrossRef]

9. Combs, S.A.; Diehl, M.D.; Filip, J.; Long, E. Short-distance walking speed tests in people with Parkinson disease: reliability, responsiveness, and validity. Gait. Posture. 2014, 39, 784-788. [CrossRef]

10. Morris, M.E.; Lansek, R.; Matyas, T.A.; Summers, J.J. Ability to modulate walking cadence remains intact in Parkinson's disease. J. Neurol. Neurosurg. Psychiatry 1994, 57, 1532-1534. [CrossRef]

11. Morris, M.E.; Morris, S.; Iansek, R. Reliability of measurements obtained with the Timed "Up \& Go" test in people with Parkinson disease. Phys. Ther. 2001, 81, 810-818. [PubMed]

12. Ferrarin, M.; Lopiano, L.; Rizzone, M.; Lanotte, M.; Bergamasco, B.; Recalcati, M. Quantitative analysis of gait in Parkinson's disease: a pilot study on the effects of bilateral sub-thalamic stimulation. Gait. Posture 2002, 16, 135-148. [CrossRef]

13. Vieregge, P.; Stolze, H.; Klein, C.; Heberlein, I. Gait quantitation in Parkinson's disease-locomotor disability and correlation to clinical rating scales. J. Neural Transmmision 1997, 104, 237-248. [CrossRef] [PubMed]

14. Adams, S.T.; Leveson, S.H. Clinical prediction rules. Br. Med. J. 2012, 344, 8312-8320. [CrossRef]

15. Kerr, G.K.; Worringham, C.J.; Cole, M.H.; Lacherez, P.F.; Wood, J.M.; Silburn, P.A. Predictors of future falls in Parkinson disease. J. Neurol. 2010, 75, 116-124. [CrossRef] 
16. Matinolli, M.; Korpelainen, J.T.; Sotaniemi, K.A.; Myllyla, V.V.; Korpelainen, R. Recurrent falls and mortality in Parkinson's disease: A prospective two-year follow-up study. Acta Neurol. Scand. 2011, 123, $193-200$. [CrossRef]

17. Hausdorff, J.M.; Lowenthal, J.; Herman, T.; Gruendlinger, L.; Peretz, C.; Giladi, N. Rhythmic auditory stimulation modulates gait variability in Parkinson's disease. Eur. J. Neurosci. 2007, 26, 2369-2375. [CrossRef]

18. Hausdorff, J.M.; Cudkowicz, M.E.; Firtion, R.; Wei, J.Y.; Goldberger, A.L. Gait variability and basal ganglia disorders: stride-to-stride variations of gait cycle timing in Parkinson's and Huntington's disease. Mov. Disord. 1998, 13, 428-437. [CrossRef]

19. Hausdorff, J.M.; Balash, J.; Giladi, N. Effects of cognitive challenge on gait variability in patients with Parkinson's disease. J. Geriatr. Psychiatry Neurol. 2003, 16, 53-58. [CrossRef]

20. Rios, D.A.; Hausdorff, J.M.; Edelberg, K.H. Gait variability and fall risk in community-living older adults: A 1-year prospective study. Arch. Phys. Med. Rehabil. 2001, 82, 1050-1060. [CrossRef]

21. Hausdorff, J.M.; Schaafsma, J.D.; Balash, Y.; Bartels, A.L.; Gurevich, T.; Giladi Nagai, K. Impaired regulation of stride variability in Parkinson's disease subjects with freezing of gait. Exp. Brain Res. 2003, 149, 187-194. [CrossRef] [PubMed]

22. Solomont, J.; Kowall, N.; Hausdorff, J.M. Influence of executive function on locomotor function: divided attention increases gait variability in Alzheimer's disease. J. Am. Geriatr. Soc. 2003, 51, 1633-1637.

23. Frenkel-Toledo, S.; Giladi, N.; Peretz, C.; Herman, T.; Gruendlinger, L.; Hausdorff, J.M. Effect of gait speed on gait rhythmicity in Parkinson's disease: variability of stride time and swing time respond differently. J. Neuroeng. Rehabil. 2005, 2, 23-26. [CrossRef] [PubMed]

24. Blin, O.; Ferrandez, A.M.; Serratrice, G. Quantitative analysis of gait in Parkinson patients: Increased variability of stride length. J. Neurol. Sci. 1990, 98, 91-97. [CrossRef]

25. Osamu, H.; Yoshitaka, S.; Toyokazu, S.; Harukazu, T. Spectral analysis of gait variability of stride interval time seires: Comparison of young, elderly and Parkinson's disease patients. J. Phys. Ther. Sci. 2009, 21, 105-111.

26. Krishnan, S.; Wu, Y. Statistical Analysis of Gait Rhythm in Patients With Parkinson's Disease. IEEE Trans. Neural. Syst. Rehabil. Eng. 2010, 18, 150-158.

27. Mena, D.; Mansour, J.M.; Simon, S.R. Analysis and synthesis of human swing leg motion during gait and its clinical applications. J. Biomech. 1981, 14, 823-832. [CrossRef]

28. Mochon, S.; McMahon, T.A. Ballistic walking. J. Biomech. 1980, 13, 49-57. [CrossRef]

29. Echeverria, J.C.; Rodriguez, E.; Velasco, A.; Alvarez-Ramirez, J. Limb dominance changes in walking evolution explored by asymmetric correlations in gait dynamics. Physica A 2010, 389, 1625-1634. [CrossRef]

30. Mirek, E.; Rudzinska, M.; Szczudlik, A. The assessment of gait disorders in patients with Parkinson's disease using the three-dimensional motion analysis system Vicon. Neurol. Neurochir. Pol. 2007, 41, 128-133.

31. Dipaola, M.; Pavan, E.E.; Cattaneo, A.; Frazzitta, G.; Pezzoli, G.; Cavallari, P.; Frigo, C.A.; Isaias, I.U. Mechanical Energy Recovery during Walking in Patients with Parkinson Disease. PLoS ONE 2016, 3, 0156420. [CrossRef] [PubMed]

32. Gabbard, C.; Hart, S. A question of foot dominance. J. Gen. Physiol. 1996, 123, 289-296. [CrossRef] [PubMed]

33. Hirokawa, S. Normal gait characteristics under temporal and distance constraints. J. Biomed. Eng. 1989, 11, 449-456. [CrossRef]

34. Sadeghi, H.; Allard, P.; Labelle, H.; Duhaime, M. Lower limb muscle powers contributions in bilateral able-bodied gait. Physiol. Ther. 2000, 80, 1188-1196. [CrossRef]

35. Hausdorff, J.M.; Lertratanakul, A.; Cudkowicz, M.E.; Peterson, A.L.; Kaliton, D.; Goldberger, A.L. Dynamic markers of altered gait rhythm in amyotrophic lateral sclerosis. J. Appl. Physiol. 2000, 88, 2045-2053. [CrossRef]

36. Moody, G.B.; Mark, R.G.; Goldberger, A.L. PhysioNet: A web-based resource for the study of physiologic signals. IEEE Eng. Med. Biol. Mag. 2001, 20, 70-75. [CrossRef]

37. Ghasemi, A.; Zahediasl, S. Normality Tests for Statistical Analysis: A Guide for Non-Statisticians. Int. J. Endocrinol. Metab. 2012, 10, 486-489. [CrossRef]

38. Siegel, C. Nonparametric Statistics for the Behavioral Sciences; McGraw-Hill: New York, NY, USA, 1988.

39. Arora, P.; Srivastava, S.; Arora, K.; Bareja, S. Improved Gait Recognition Using Gradient Histogram Gaussian Image. Procedia Comput. Sci. 2015, 58, 408-413. [CrossRef] 
40. Ota, L.; Uchitomi, H.; Hove, M.J.; Orimo, S. Evaluation of severity of Parkinson's disease using stride interval variability. In Proceedings of the 2012 ICME International Conference on Complex Medical Engineering, Kobe, Japan, 1-4 July 2012; Volume 4, pp. 521-526.

41. Olmo, D.; Cudeiro, J. Temporal variability of gait in Parkinson disease: effects of a rehabilitation programme based on rhythmic sound cues. Parkinsonism. Relat. Disord. 2005, 11, 25-33. [CrossRef]

42. Hausdorff, J.M. Gait variability: Methods, modeling and meaning. J. Neuroeng. Rehabil. 2005, 2, 19. [CrossRef]

43. Baltadjieva, R.; Giladi, N.; Gruendlinger, L.; Peretz, C.; Hausdorff, J.M. Marked alterations in the gait timing and rhythmicity of patients with de novo Parkinson's disease. Eur. J. Neurosci. 2006, 24, 1815-1820. [CrossRef] [PubMed]

44. Schaafsma, J.D.; Giladi, N.; Balash, Y.; Bartels, A.L.; Gurevich, T.; Hausdorff, J.M. Gait dynamics in Parkinson's disease: relationship to Parkinsonian features, falls and response to levodopa. J. Neurol. Sci. 2003, 212, 47-53. [CrossRef]

45. Gray, P.; Hildebrand, K. Fall risk factors in Parkinson's disease. J. Neurosci. Nurs. 2000, 32, $222-228$. [CrossRef] [PubMed]

46. Plotnik, M.; Giladi, N.; Hausdorff, J.M. Postural instability and fall risk in Parkinson's disease: impaired dual tasking, pacing, and bilateral coordination of gait during the "ON" medication state. Exp. Brain Res. 2011, 210, 529-538. [CrossRef]

47. Weaver, T.B.; Robinovitch, S.N.; Laing, A.C.; Yang, Y. Falls and Parkinson's Disease: Evidence from Video Recordings of Actual Fall Events. J. Am. Geriatr. Soc. 2016, 64, 96-101. [CrossRef]

(C) 2020 by the authors. Licensee MDPI, Basel, Switzerland. This article is an open access article distributed under the terms and conditions of the Creative Commons Attribution (CC BY) license (http://creativecommons.org/licenses/by/4.0/). 